\title{
INTERACTION OF ALBUMIN AND IMMUNOGLOBULIN G WITH SYNTHETIC HYDROXYAPATITE
}

\author{
Pylypchuk E. V., Mishchenko Valentin N., Gromovoy Taras Yu.* \\ O. Chuiko Institute of Surface Chemistry. National Academy of Sciences of Ukraine, \\ Gen. Naumova 17, 03164 Kyiv-164, Ukraine \\ *Corresponding author: e-mail:gromovoy@mail.md,tel:+38-044-4249456
}

\begin{abstract}
It was shown by X-ray phase analysis, IR spectra analysis and MALDI-ToF mass spectrometry methods that interaction of synthetic hydroxyapatite with a solution of immunoglobulin $\mathrm{G}$ leads to its partial dissolution due to leaching from the surface of calcium triphosphate which, in our opinion, forms complexes with immunoglobulin G.
\end{abstract}

Keywords: MALDI-ToF, X-ray phase analysis, albumin, immunoglobulin G, hydroxyapatite, interaction.

\section{Introduction}

Hydroxyapatite ( $\left.\mathrm{HA}, \mathrm{Ca}_{10}\left(\mathrm{PO}_{4}\right)_{6}(\mathrm{OH})_{2}\right)$ is a synthetic analogue of the mineral component of bone and is widely used in catalysis, adsorption, laser technology and other fields [1]. Its most promising application is as implant in biological systems, due to its good biocompatibility and chemical affinity to the mineral basis of bone, that is, to the calcified tissues. On the other hand, synthetic calcium phosphates do not fully possess biological properties of the bone tissues [2]. This is due to some differences in chemical composition as bone contains calcium phosphates, which have also carbonates, phosphate, trace elements, etc. In turn, the chemical differences contribute to making changes in the texture of the material [3]. At the same time, the mineral component of bone tissue in the body fluids is susceptible to partial dissolution, but to a lesser extent than synthetic HA, which is associated with the presence of some trace elements in natural materials [4-5].

The latter considerations justify the need to study synthetic HA in contact with body fluids to determine possible ways of its dissolution.

As a model system we have chosen HA-immunoglobulin $\mathrm{G}(\mathrm{IgG})$ and HA-human serum albumin (HSA). We studied the interaction of these components.

\section{Materials and methods}

HA synthesis [14-15]

HA was synthesized using commercially available $\mathrm{Ca}\left(\mathrm{NO}_{3}\right)_{2}\left(99 \%\right.$ ACS, Aldrich) and $\left(\mathrm{NH}_{4}\right)_{2} \mathrm{HPO}_{4}$ (Aldrich) as starting precursors. The reaction was conducted using de-ionized water. The method consisted of the following steps. Stoichiometric amount of $\mathrm{Ca}\left(\mathrm{NO}_{3}\right)_{2}(0.1 \mathrm{M})$ was first dissolved in $100 \mathrm{ml}$ water and $25 \%$ ammonia in water was added until $\mathrm{pH}=10$ (solution \#1). At the same time stoichiometric amount of $\left(\mathrm{NH}_{4}\right)_{2} \mathrm{HPO}_{4}(0.1 \mathrm{M})$ was dissolved in $100 \mathrm{ml}$ water and $25 \%$ ammonia in water was added until $\mathrm{pH}=10$ (solution \#2). Then solution \#2 dropwise was added to solution \#1 with continuous stirring. Upon completion of addition the resulting solution was heated on boiling for 10 minutes. Solution was left at room temperature for $24 \mathrm{~h}$. The resulting precipitate was filtered and dried in air at $110^{\circ} \mathrm{C}$.

Chemical precipitation route can be represented by the following reaction:

\section{Preparations of $\operatorname{Ig} G$ and $H S A$}

$$
10 \mathrm{Ca}\left(\mathrm{NO}_{3}\right)_{2}+6\left(\mathrm{NH}_{4}\right)_{2} \mathrm{HPO}_{4}+2 \mathrm{H}_{2} \mathrm{O} \rightarrow \mathrm{Ca}_{10}\left(\mathrm{PO}_{4}\right)_{6}(\mathrm{OH})_{2}+12 \mathrm{NH}_{4} \mathrm{NO}_{3}+8 \mathrm{HNO}_{3}
$$

IgG and HSA were dissolved in water to a concentration of $1 \mathrm{mg} / \mathrm{ml}$. To $1 \mathrm{ml}$ of IgG or HSA 20 or $100 \mathrm{mg}$ of HA were added. After incubation at room temperature, the solution of HA with proteins was centrifuged at $10000 / \mathrm{min}$ for 15 minutes. The supernatant was investigated by MALDI. The sediments were examined by XRD HA and IR.

MALDI-ToF

Matrix for the mass spectrometric studies were prepared by standard procedures: $12 \mathrm{mg}$ of SA (Sinapic Acid Fluka (SA)) (Sigma) was dissolved in $1 \mathrm{ml}$ water-acetonitrile mixture in the ratio 1:1. To the solution trifluoroacetic acid was added in $1 \mathrm{mkl}$ aliquots [6].

The studies were conducted in the range of $19 \mathrm{kDa}-300 \mathrm{kDa}$. The resulting spectrum is the result of the accumulation of 600 single spectra.

IR spectra

IR spectra were recorded on a spectrophotometer "Perkin Elmer" (Model 1720H) in the range of 400$4000 \mathrm{~cm}^{-1}$. 
$X$-ray phase analysis

DRON-UM1 using K $\alpha$ radiation anode $\mathrm{x}$-ray focusing Bragg-Brentano, Co K $(\lambda=0,179021 \mathrm{~nm})$ and Fe - in the filter the reflected rays.

\section{Results and discussion}

MALDI mass spectrum of $\operatorname{IgG}$ is represented by a series of peaks which include the molecular ion $\operatorname{IgG}+(150$ $\mathrm{kDa}$ ) and the various possible combinations of singly-charged fragments of IgG formed by cleavage of its light ( $23 \mathrm{kDa})$ and heavy $(50 \mathrm{kDa})$ chains. The obtained mass spectrum and its interpretation matches previously published data [7].

As a control, HA samples of two different concentrations (20 and $100 \mathrm{mg} \backslash \mathrm{ml})$ were incubated in distillates for 2 and 24 hours. After centrifugation, the supernatant was treated with IgG and albumin (separately) and kept for $2 \mathrm{~h}$ and $24 \mathrm{~h}$. Then the solution was investigated by MALDI. No changes in the mass spectra of proteins have been recorded. Consequently, all subsequent changes in the mass spectra of proteins are the result of their interactions with HA.

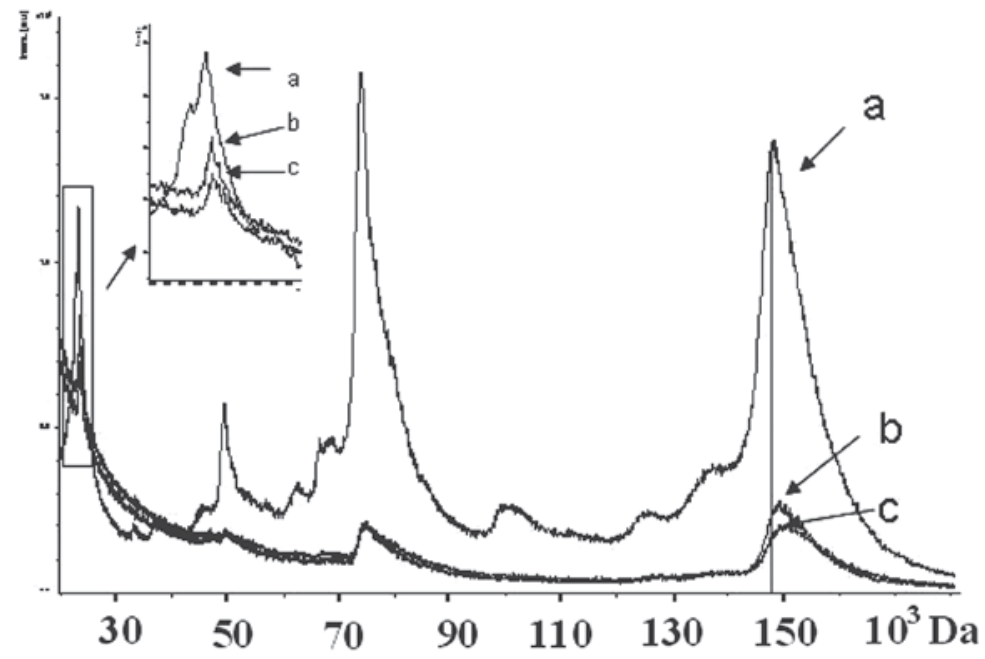

Fig. 1. MALDI-TOF mass spectrum of $\operatorname{IgG}(\mathrm{a})$, after one hour of incubation (b), and 4-hour incubation (d) in the presence of $100 \mathrm{mg} / \mathrm{ml}$ of HA in positive mode.

After exposure of the solution with HA IgG $(20 \mathrm{mg} / \mathrm{ml})$ changes have been observed in the mass spectrum of positive ions, namely an increase in the mass values of the corresponding peaks. Since the molecular ion of $\operatorname{IgG}+$ shifted by about 520 amu and 1500 amu after 2 and 4-hour incubations, respectively. With increasing concentration of HA to $100 \mathrm{mg} / \mathrm{ml}$ more critical changes of mass values were observed (Figure 1). The increase in mass of the ion IgG was 1000 amu and $2200 \mathrm{amu}$ in 2 and 4-hour incubations, respectively. The mass of heavy IgG fragment increased by $700 \mathrm{amu}$ after $2 \mathrm{~h}$ incubation and remained so after 4 hours of incubation. The change in the mass of light fragment of $\operatorname{IgG}$ at 220 amu in 2 and 4 hours of incubation was noted. This indicates that the light chains of IgG are involved in interaction with the inorganic surface, which is fundamentally different from the mechanism of the interaction of $\operatorname{IgG}$ with salts of heavy metals, which have been recorded by their interaction with light chain protein [8]. A similar exhibition of HA in solution of HSA did not lead to a change in mass of the protein even at $24 \mathrm{~h}$ incubation. The general trend for the HSA and IgG represents a decrease in the relative intensities of the ions in the mass spectrum with increasing concentration of HA and the exposure time, which is related to processes of proteins adsorption on HA.

To assess the state of GA, after interaction with IgG, we used the method of IR spectroscopy, which is able to detect the presence of such a local change of symmetry, and phosphate anions that make up the architecture and surface properties of HA.

Figure 2 shows the IR spectra of HA, HA with adsorbed IgG and HA with adsorbed IgG after repetitive washing with water.

It is noteworthy, that in the original HA characteristic bands in the region $400-800 \mathrm{~cm}^{-1}$ are due mainly to deformation vibrations of $-\mathrm{PO}_{4}$ tetrahedrons and the bands in the region $900-1200 \mathrm{~cm}^{-1}$ - stretching vibrations of the phosphate anion (P-O bonds). The bands in the range 1300-1650 cm-1 and about $873 \mathrm{~cm}^{-1}$ correspond to the $\mathrm{v} 3$ and $\mathrm{v} 2$ modes of vibrations of carbonate groups. Deformation vibrations of water molecules are located at $1620 \mathrm{~cm}^{-1}$. The broad absorption band in the range $2500-3700 \mathrm{~cm}^{-1}$ refers to water adsorption. 


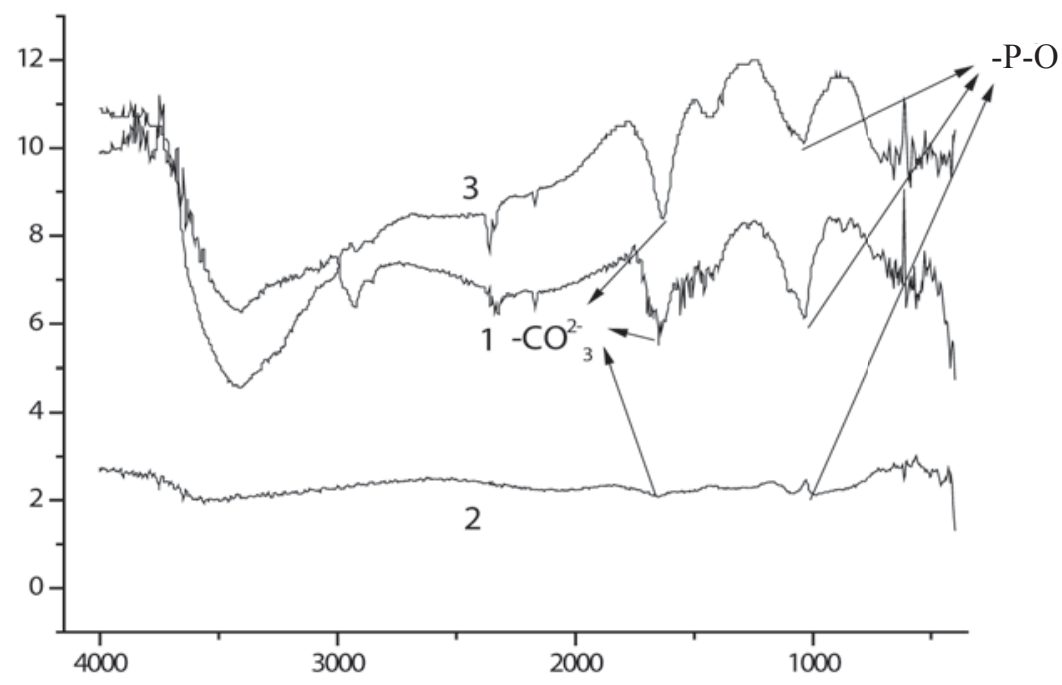

Fig. 2. IR spectra of HA (1), with adsorbed $\operatorname{IgG}(2)$ and after washing (3)

After interaction with a solution of IgG following changes are observed in the IR spectrum. The intensity of the characteristic absorption bands changes, as well as the observed shift of their maxima. An increase of the intensity of the bands at $601 \mathrm{~cm}^{-1}$ for the HA protein with adsorbed IgG is detected, along with a simultaneous decrease in the intensity of the absorption band at $562 \mathrm{~cm}^{-1}$ compared to the original HA indicating the involvement of $\mathrm{P}-\mathrm{OH}$ bonds in the process of protein adsorption. The structure of the absorption band at $1700-1600 \mathrm{~cm}^{-1}$ the largest contribution corresponds to the $\mathrm{C}=\mathrm{O}$ group in the peptide bond $(80 \%)$ with a small contribution of plane bending vibrations of $\mathrm{NH}$ groups $(10 \%)$ and valence vibrations of C-N bond (10\%). Peptide groups form hydrogen bonds that define secondary structure of proteins. According to literature data, in aqueous solution it is dominated by the structure of $\beta$-sheet (the peak of $1638 \mathrm{~cm}^{-1}$, which is clearly visible in the spectrum of HA and protein), which is changed or even destroyed after the interaction in the HA. The absorption bands of carbonate groups are becoming more distinct and separate too, which can be explained by immunoglobuline "nanogrinding" the IgG surface and by the involvement of the HA surface acid centers on that process. Considering the analysis of the IR spectra suggests that the interaction of IgG molecules with the HA surface, assumes involvement of $-\mathrm{PO}_{4}$ tetrahedrons, which leads to their partial polarization, change of geometry and as a consequence changing the bond lengths. After washing the protein from the surface of HA a partial restoration of the original form of the spectrum is observed, indicating a partial restoration of HA structure after washing.

Information about changes in the structure of $\mathrm{HA}$ after interaction with the protein was supplemented by X-ray phase analysis (Figure 3). It is noted that the ratio of the intensity of the reflection (28 deg) decreases with respect to the reflex in the $(29 \mathrm{deg}$.). However, the protein is partially returned to its original position after desorption. It should be noted that in the synthetic HA there is always about $5 \%$ of tricalcium phosphate (TCP) [12], whose lines are just in the 28-29 deg and their intensity changes after washing the protein.

The degree of conversion of TCP to HA was determined by the formula [9]:

$$
R_{n}=\frac{I_{\mathrm{HA}}}{I_{\mathrm{HA}}+I_{\mathrm{TCP}}} .
$$

For pure HA it was obtained the value $\mathrm{Rn}=0,79$, for the HA with immune globulin after washing $\mathrm{Rn}=0,8$ indicating the decrease of TCP share in HA.

According to the XRD average particle size constitutes $36 \mathrm{~nm}$ [11]. Amount of $\beta$-TCP impurity, according to the standard JCPDS 9-169, which is always present in the synthetic HA is $\sim 5 \%$ (within the sensitivity of XRD). If we assume that the particles have a spherical shape, we can determine the surface area of nanoparticles and, therefore, estimate the area occupied by the TCP. We have identified the surface area of sphere particles representing $2826 \mathrm{~nm}^{2}$, of them $148 \mathrm{~nm}^{2}$ falls on the surface occupied by the TCP. Obviously, the percentage contribution of TCP structure, which in our opinion determines the characteristic changes in all the spectra related to IgG experiments, is negligible as compared to other parts of the surface and particle volume. This shows little change in the intensities of reflections of X-ray diffraction and transmission lines in the IR spectra. There are also data in the literature to explain the change in the diffraction patterns. According to the authors, the abrupt change in the diffraction patterns shows the transition from mono-crystalline to poly-crystalline HA with $2 \theta$ in the range of 31.5 and 33.2 deg [13]. 


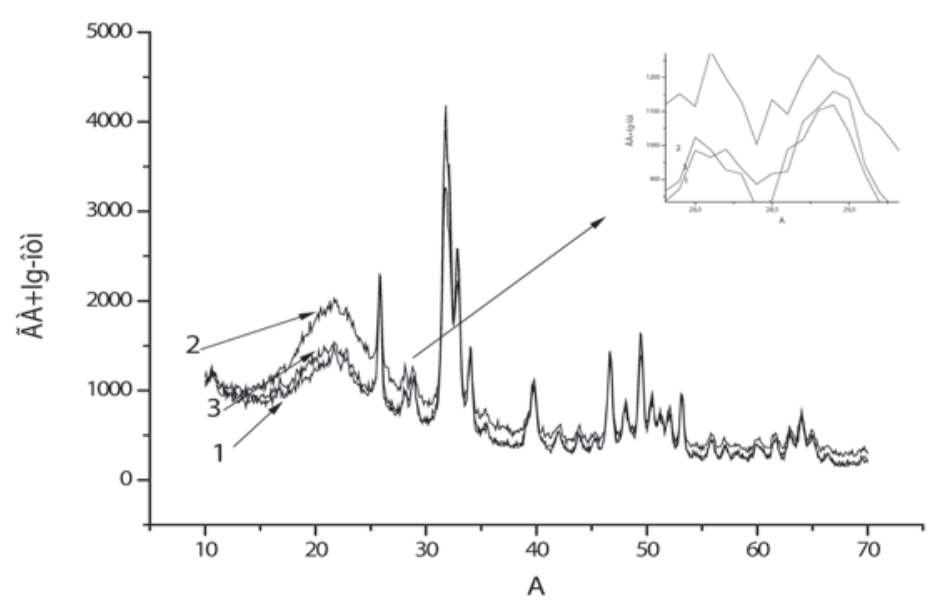

Fig. 3. XRD for the HA (3), IgG (2) and after washing the adsorbed protein (1)

It was previously shown the possibility to influence the structure of inorganic phosphate with amino acids, namely, that some of them are able to transform amorphous calcium phosphates in monocrystalline HA and participate in the structuring of the surface [9] and asparagine can produce changes in the structure of calcium hydrogen phosphate surface in 72 hours [10]. Theoretical studies have shown that the interaction of aminoacids with HA surface is associated with changes in the geometry of the surface groups with a change in bond lengths [9].

\section{Conclusions}

In connection with the above, we conclude that the HA interactions with a solution of IgG leads to its partial dissolution due to leaching from the surface of calcium triphosphate which, in our opinion, forms complexes with IgG. The interaction of HA and IgG acquire new qualities: HA alters the chemistry and structure of the surface and the IgG in complex with fragments of the surface of HA, which may lead to a change in its biological activity. To answer the question why such changes occur in the case of IgG but not of HAS, further investigations must be conducted.

\section{References}

[1]. Vorona, I. P.; Baran, N. P.; Ishchenko, S. S.; Rudko, V. V. and Chumakova, L. S. Physics of the Solid State, 2008, 50 (10), p. 1852-1856.

[2]. Shi, D. Biomaterials and Tissue Engineering, Springer Berlin Heidelberg, New York 2004, p. 2.

[3]. Lanza, R.; Lagner, R.; Chick, W. Principles of Tissue Engineering. Academic Press Inc.,San Diego CA 1997, p. 603.

[4]. Mezahi, F.; Oudadesse, H.; Harabi, A.; Lucas-Girot, A.; Gal, Y.; Chaair, H. Cathelineau Journal of Thermal Analysis and Calorimetry. 2009, 95(1), p. 21-29.

[5]. Iafisco, M.; Varoni, E.; Di Foggia, M.; Pietronavea, S.; Fini, M.; Roveri, N.; Rimondini, L.; Prat, M. Colloids and Surfaces B: Biointerfaces. 2012, 90, p. 1-7.

[6]. Hortin, G.L. Clinical Chemistry, 2006, 52, p. 1223-1237.

[7]. Roitt, I.; Brostoff, J.; Male, D. Immunology(5 th edition) 1998, Mosby p. 321.

[8]. Trakhtenberg, I.M.; Gromovoy, T.Yu.; Pokrovskiy, V.A.; Dmytrukha, N.N.; Shevchenko, G.V. Contemporary problems of toxicology (Ukraine) 2009, p. 37-40.

[9]. Rimola, A.; Corno, M.; Marcelo Zicovich-Wilson, C. and Ugliengo, P. J. Am. Chem. Soc., 2008, 130 (48), p. $16181-16183$.

[10]. Chu, X.; Jiang, W.; Zhang, Z.; Yan, Y.; Pan, H.; Xu, X.; Tang, R. J. Phys. Chem. B. 2011, 115(5), p. 1151.

[11]. Scherrer, P. Nachr. Ges. Wiss. Goettingen, Math.-Phys., 1918, B. 26. S. 98-100.

[12]. Tsuber, V.K.; Lesnikovich, L.A.; Kulak, A.I.; Trofimova, I.V. and Petrov, P.T. Pharmaceutical Chemistry Journal. 2006, 40 (8), p. 455-458.

[13]. Pang, Y.X.; Bao, X. J. Eur. Ceram. Soc., 2003, 23, p. 1697-1704.

[14]. Tagai H, Aoki H. In: Hastings GW, Williams DF, editors. Preparation of synthetic hydroxyapatite and sintering of apatite ceramics; mechanical properties of biomaterials. John Wiley \&Sons, Ltd.; 1987. p. 213.

[15]. Jarcho M, Bolen C, Thomas M, Bodick J, Kay J, Doremus R. JMater Sci 1976;11(11):2027. 